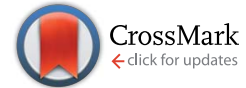

Cite this: J. Mater. Chem. A, 2015, 3, 16097

\section{Large formamidinium lead trihalide perovskite solar cells using chemical vapor deposition with high reproducibility and tunable chlorine concentrations $\uparrow$}

\begin{abstract}
Matthew R. Leyden, Michael V. Lee, Sonia R. Raga and Yabing Qi*
Chemical vapor deposition is an inexpensive way to batch-process solar cells with good uniformity and facilitates low-cost production. Formamidinium lead iodide perovskite has a smaller energy band gap and greater potential efficiency than the widely studied methylammonium lead iodide perovskite and better temperature stability. This work is the first demonstration of vapor deposition of formamidiniumbased perovskite. A self-limiting perovskite formation process is recommended, with efficiencies as high as $14.2 \%$ and stability up to 155 days after fabrication. Using this process, a batch of semi-transparent solar cells with a large area of $1 \mathrm{~cm}^{2}$ was fabricated. We monitored the growth of perovskite in real time and provide insight that may not be accessible for a solution based process. We directly measured chlorine in perovskite films and correlated the concentration of chlorine with efficiency and stability.
\end{abstract}

Received 15th May 2015

Accepted 29th June 2015

DOI: $10.1039 / \mathrm{c} 5$ ta03577e

www.rsc.org/MaterialsA work shows that formamidinium iodide (FAI)-based perovskite is a promising alternative to the widely studied methylammonium-based perovskite for solar cell applications. Solar cells typically need to operate under high temperature conditions, and FAI perovskite's improved temperature stability will facilitate a longer lifetime. ${ }^{17}$ Furthermore, the smaller energy band gap of $\sim 1.5 \mathrm{eV}$ of FAI solar cells has a broader absorption band and potentially better performance. The current record PSC uses FAI containing perovskite. ${ }^{4}$ To date, almost all solar cells made with FAI have been prepared using a solution process. ${ }^{17-28}$ CVD offers an inexpensive way to scale-up PSCs because it is amenable to batch-processing. In addition to a higher throughput, batch processing can improve sample-tosample uniformity. The self-limiting nature of perovskite formation by CVD improves batch-to-batch reproducibility. Furthermore, because perovskite growth is performed at temperatures commonly used for annealing, no additional annealing step is required, which improves reproducibility and reduces equipment requirements. This work is the first demonstration of fabrication of FAI-based PSCs using CVD that are stable even after 155 days, with efficiencies as high as $14.2 \%$. Solar cells with areas as large as $1 \mathrm{~cm}^{2}$ provide efficiencies reaching $7.7 \%$.

\section{Results and discussion}

\section{Perovskite solar cells fabricated by CVD}

Perovskite was formed in a 2-step process, in which a thin film of lead halide was first deposited onto substrates pre-deposited with a $\mathrm{TiO}_{2}$ blocking layer. These substrates were loaded into
Technology Graduate University (OIST), 1919-1 Tancha, Onna-son, Okinawa 904-0495, Japan.E-mail: Yabing.Qi@OIST.jp

$\dagger$ Electronic supplementary information (ESI) available. See DOI: 10.1039/c5ta03577e 
one zone of a CVD tube furnace and FAI was loaded into a separate zone (Fig. 1a). The tube was then evacuated and purged with dry nitrogen. Substrates were first ramped up to $160{ }^{\circ} \mathrm{C}$. Thereafter, the FAI source material was heated to $180{ }^{\circ} \mathrm{C}$, causing it to sublimate. Typically, $\mathrm{PbCl}_{2}$ is thermally evaporated to a thickness of $100 \mathrm{~nm}$. Upon full saturation with FAI, the film thickness increased from $103 \pm 2 \mathrm{~nm}\left(\mathrm{PbCl}_{2}\right)$ to $324 \pm 6 \mathrm{~nm}$ (perovskite). A completed solar cell would be coated with a hole transport layer made of spiro-MeOTAD, and would have gold top contacts (Fig. 1b).

\section{FAI deposition}

Under these growth conditions, FAI deposition appears to be largely mass transport-limited, meaning that the rate of conversion from $\mathrm{PbCl}_{2}$ to perovskite is limited by the amount of FAI transported to the substrate in the vapor phase. The amount of FAI deposited onto a substrate is dependent on a number of factors, such as the temperature of the FAI crucible, deposition time, surface area of the FAI, position, orientation, and packing density of substrates within the CVD. All of these factors were observed to affect growth and can be well controlled in a CVD process. Position dependence is more noticeable at lower temperatures (i.e. $120^{\circ} \mathrm{C}$ ), where substrates along the length of the CVD tube furnace develop a variety of colors despite having experienced the same nominal process (Fig. 2a and ESI video $\dagger$ ). All positions transited all of the phases shown, (E-A), as long as the CVD process was allowed to progress. Improved uniformity is observed at temperatures above $\sim 145{ }^{\circ} \mathrm{C}$, due to the inability of FAI to condense onto the sidewalls of the tube. This prevents formation of steep concentration gradients of FAI vapor below its sublimation temperature $\left(\sim 145^{\circ} \mathrm{C}\right)$. Therefore, it is possible to perform depositions on plastic substrates as long as the

\section{a)}

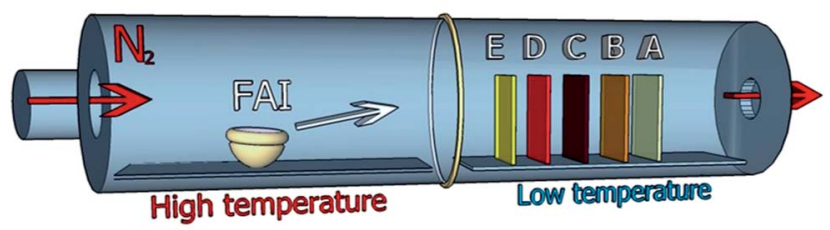

b)

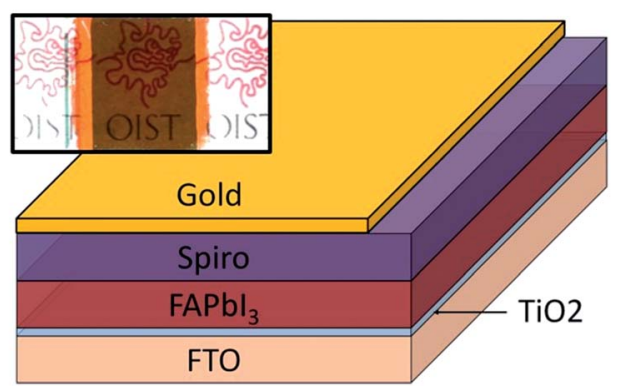

Fig. 1 Schematic of perovskite growth and device structure. (a) Schematic of a chemical vapor deposition system for the growth of perovskite on substrates pre-deposited with $\mathrm{PbCl}_{2}$. (b) Diagram of the layered structure of a completed perovskite solar cell. The inset is a photograph of a $1 \mathrm{~cm}^{2}$ completed cell with a thin transparent gold top contact. plastics maintain their integrity at the temperature used. Lower temperatures may require a temperature gradient, creating a reaction rate gradient that accommodates the concentration gradient. All devices were grown at $160{ }^{\circ} \mathrm{C}$ to ensure that substrates were well above the FAI sublimation temperature and to maximize rates of reaction and crystal growth. Growth was observed in situ and was recorded. Videos showing this growth are included in the ESI. $\dagger$

\section{Phases of perovskite film growth}

During CVD growth, there are three possible phases of the thin film, depending on the amount of FAI deposited. First, $\mathrm{PbCl}_{2}$ is

a)

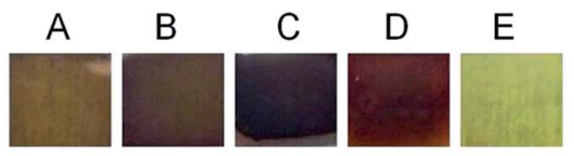

FAI Concentration

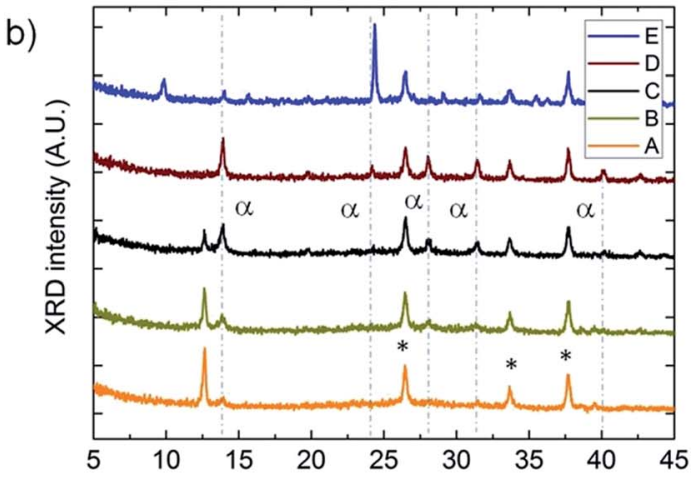

$2 \theta$

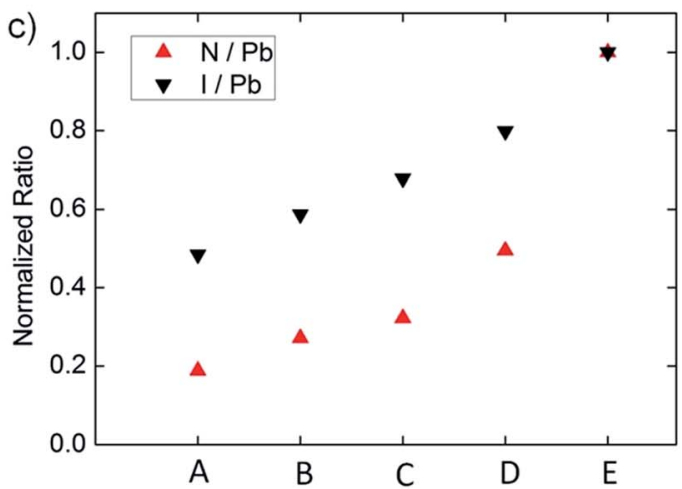

Fig. 2 Phases of FAl-based perovskite growth. (a) Photographs of films on FTO glass at different stages of perovskite growth caused by an FAI concentration gradient. The thickness of the films from $A$ to $E$ was measured to be 117, 133, 161, 278, and $489 \mathrm{~nm}$. (b) X-ray diffraction spectra of samples A-E. Crystal peaks originating from trigonal $P 3 \mathrm{~m} 1$ perovskite are identified with an $\alpha$ and a dashed line. Peaks from the substrate are marked with a star (*). (c) X-ray photoelectron spectra (XPS) of samples A-E. This graph shows XPS intensity of iodine and nitrogen peaks relative to lead peaks, normalized to sample $E$. These spectra show that the concentrations of iodine and nitrogen increase from $\mathrm{A}$ to $\mathrm{E}$. This confirms that the different samples correspond to different concentrations of $\mathrm{FAl}$ and the concentration of $\mathrm{FAl}$ is responsible for the different phases. 
mostly converted to lead iodide, this is consistent with the yellow color, the appearance of an X-ray diffraction (XRD) peak at $12.6^{\circ}$ (Fig. 2b), and the X-ray photon spectroscopy (XPS) measurement of the lead to iodide ratio of approximately $2: 1$ (Fig. S1†).

At higher concentrations of FAI, the film begins to form perovskite and turns from yellow to black. XRD peaks form at $13.9^{\circ}, 28.0^{\circ}$, and $31.5^{\circ}$. With enough FAI for complete conversion, the film appears red in color and XRD peaks at $24.4^{\circ}$ and $40.2^{\circ}$ appear. These 5 peaks are consistent with trigonal perovskite in the $P 3 m 1$ space group. ${ }^{29}$ At this stage, there is a defined absorption edge at $\sim 830 \pm 10 \mathrm{~nm}(1.50 \mathrm{eV})$ in the UV-vis spectrum (Fig. S2†).

With increasing FAI, the film becomes oversaturated. It transitions from red to yellow, and a new yellow crystal structure forms with peaks at $9.9^{\circ}, 15.7^{\circ}$, and $29.1^{\circ}$. Adding even more FAI causes the film to become comparatively opaque and creates new peaks at $18.0^{\circ}, 25.7^{\circ}, 27.0^{\circ}$, and $30.7^{\circ}$ (Fig. S3†). FAI powder measured by XRD was found to have prominent peaks at $18.5^{\circ}$, $25.8^{\circ}, 36.5^{\circ}$ and $44.4^{\circ}$ (Fig. S3 $\dagger^{\dagger}$ ). Based on XRD and UV-vis results, at least 2 lead-FAI-based crystal structures other than perovskite, $\delta$-phase perovskite, ${ }^{27}$ or bulk FAI can form during the CVD process. It would be interesting to characterize the structure of these yellow phases in more detail, but that is beyond the scope of this study.

Again, under low temperature conditions there is a gradient in the FAI vapor concentration along the length of the CVD tube. Samples have progressively less FAI deposited with increasing distance from the FAI source (from E to A) (Fig. 1). XPS was performed to confirm that sample $\mathrm{E}$ has more FAI than sample A. From the XPS spectrum, it is possible to measure the relative ratios of iodine and nitrogen relative to lead. Because all nitrogen in the samples comes from FAI, the gradient in the FAI concentration in samples E-A is confirmed by XPS results (Fig. 2d) and the FAI concentration determines the phase.

\section{FAI saturation and device performance}

Five representative batches of solar cells were fabricated, each with variable FAI deposition and heating times. These batches represent differing levels of FAI absorbed into the perovskite film, or levels of "saturation". The degree of saturation is determined by visually monitoring the growth in situ. Details of each run are provided in the ESI. $\dagger$ In the first batch, source FAI was kept at $180^{\circ} \mathrm{C}$ for a short time, and consequently this batch is believed to have been slightly undersaturated with FAI and devices fabricated had an average efficiency of $10.5 \% \pm 0.7 \%$ (Tables 1 and S1, Fig. 3, and ESI video $\dagger$ ). To test the roles of packing density and orientation, FTO glass substrates were loaded vertically, otherwise the CVD process was kept the same. This batch had a lower average efficiency of $7.8 \% \pm 1.3 \%$, which is likely due to being highly undersaturated with FAI. This suggests that FAI deposition depends on how substrates are loaded; tightly packed substrates take a longer time to convert to perovskite than loosely packed samples.

A third batch was controlled by watching the batch and reducing the applied heat when substrates appeared to be
Table 1 Optimal FAI saturation for solar cell performance. The table shows average values of solar cell metrics at different levels of FAl saturation, including open circuit voltage $\left(V_{o c}\right)$, short circuit current $\left(J_{\mathrm{sc}}\right)$, fill factor $(\mathrm{FF})$, and efficiency (PCE\%). This table shows there is an optimal level of FAl saturation for device performance

\begin{tabular}{llllc}
\hline & $V_{\mathrm{oc}}$ & $J_{\mathrm{sc}}\left(\mathrm{mA} \mathrm{cm}^{-2}\right)$ & FF & PCE (\%) \\
\hline Highly undersaturated & 0.90 & 17.2 & 51 & 7.8 \\
Undersaturated & 0.97 & 19.5 & 56 & 10.5 \\
Saturated & 0.97 & 21.6 & 62 & 13.0 \\
Oversaturated & 0.99 & 20.4 & 57 & 11.5 \\
Highly oversaturated & 0.93 & 18.5 & 46 & 8.0
\end{tabular}

a)

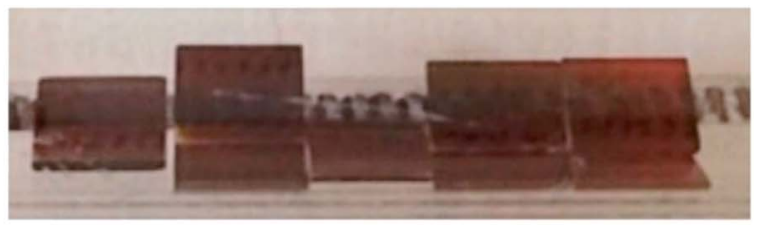

b)
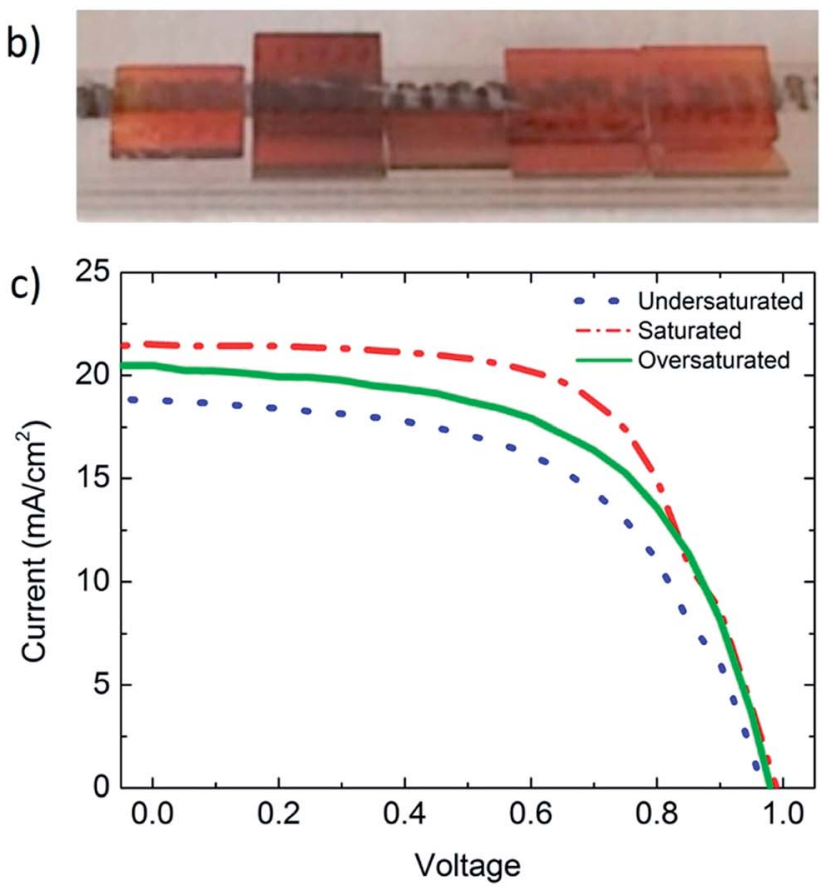

Fig. 3 Impact of FAl saturation levels on the fill factor and $J_{\text {sc. }}$ (a) Image from in situ monitoring of growth where substrates are saturated with FAl. (b) Image from the same growth, where substrates are oversaturated with FAl. (c) The graph shows representative $I-V$ curves from three relevant batches. Changes in the saturation level primarily impact the fill factor and $J_{\mathrm{sc}}$. The curves shown best represent the characteristics of the batch average, not the highest performing device. The active area of the representative curves is saturated $0.12 \mathrm{~cm}^{2}$, undersaturated $0.135 \mathrm{~cm}^{2}$, and oversaturated $0.04 \mathrm{~cm}^{2}$.

saturated. This batch was completely saturated, but did not turn yellow like Fig. 2e, and showed the highest batch average efficiency of $13.0 \% \pm 0.2 \%$.

The perovskite formation process is reversible, in that films in the saturated yellow phase transitioned back to the perovskite phase when the FAI heat source was turned off and the 
substrate was kept at $160{ }^{\circ} \mathrm{C}$ (Fig. S3 and video $\dagger$ ). This reversibility makes the CVD process more robust and easier to scale up, because it may be difficult to precisely control the amount of deposited FAI over the entire length of the CVD tube. A selflimiting desorption process ensures that substrates complete perovskite formation despite variations in saturation. A fourth batch was oversaturated with FAI, this growth was held at $160^{\circ} \mathrm{C}$ for $1 \mathrm{~h}$, which de-saturated the perovskite after the FAI heat source was turned off. This batch had an average efficiency of $11.5 \pm 1.0 \%$. A steady state measurement operating at $0.75 \mathrm{~V}$ was taken from the champion cell of this batch and gave a current density of $15 \mathrm{~mA} \mathrm{~cm}{ }^{-2}$, corresponding to a PCE of 11.3\% (Fig. S8†).

\section{Large-area solar cells}

A batch with high oversaturation was fabricated with an area of $1 \mathrm{~cm}^{2}$ and showed efficiencies as high as $7.7 \%$ (Fig. S5†). This efficiency was measured after 4 days of air exposure without encapsulation, which shows promise for long-term stability $\left(\sim 23{ }^{\circ} \mathrm{C}\right.$ and $40-50 \%$ relative humidity). The completed device (i.e. with $\mathrm{Au}$ top electrodes) was uniform in color and semitransparent, demonstrating that PSCs made with CVD are compatible for applications such as solar windows.

\section{Grain size, phase history, and efficiency}

One reason for the decreased efficiency of oversaturated perovskite is apparent from atomic force microscopy images of the surface morphology (Fig. 4). The apparent grain size of oversaturated batches is smaller $(730 \mathrm{~nm} \pm 360 \mathrm{~nm})$ than that of saturated batches $(970 \mathrm{~nm} \pm 420 \mathrm{~nm})$. Oversaturated samples likely have smaller grains because they must first convert from perovskite to the "yellow phase," and then upon desorption of FAI, they must convert back to perovskite. This means that oversaturated films make comparatively larger changes in the crystal structure in roughly the same time as films that never converted to "yellow phase." This decrease in size is more pronounced when films are highly oversaturated $(500 \mathrm{~nm} \pm$ $230 \mathrm{~nm})$.

\section{Chlorine concentration and efficiency}

Despite the apparent conversion of $\mathrm{PbCl}_{2}$ to $\mathrm{PbI}_{2}$, samples grown with an initial $\mathrm{PbI}_{2}$ layer consistently had lower $V_{\mathrm{oc}}$ and fill factors than samples made with $\mathrm{PbCl}_{2}$, even when samples were grown in the same CVD batch, or had similar grain sizes (Table S1 and Fig. S6 $\dagger$ ). This suggests that another mechanism related to chloride ions improves performance. In this study, chlorine was not directly detected by either XPS or XRD, but was detectable in time-of-flight secondary ion mass spectroscopy (ToF-SIMS). Perovskite samples similar to those formed in Fig. 2a were grown on glass, (labeled A2-E2 to differentiate this batch from previous samples on FTO). Samples A2, C2 and E2 were measured by ToF-SIMS (Fig. 5). All three samples showed insignificant numbers of chloride ions on the top surface, but significant numbers near the bottom for samples A2 and C2. Furthermore, chlorine measured near the bottom surface decreased with increasing FAI saturation. This is consistent
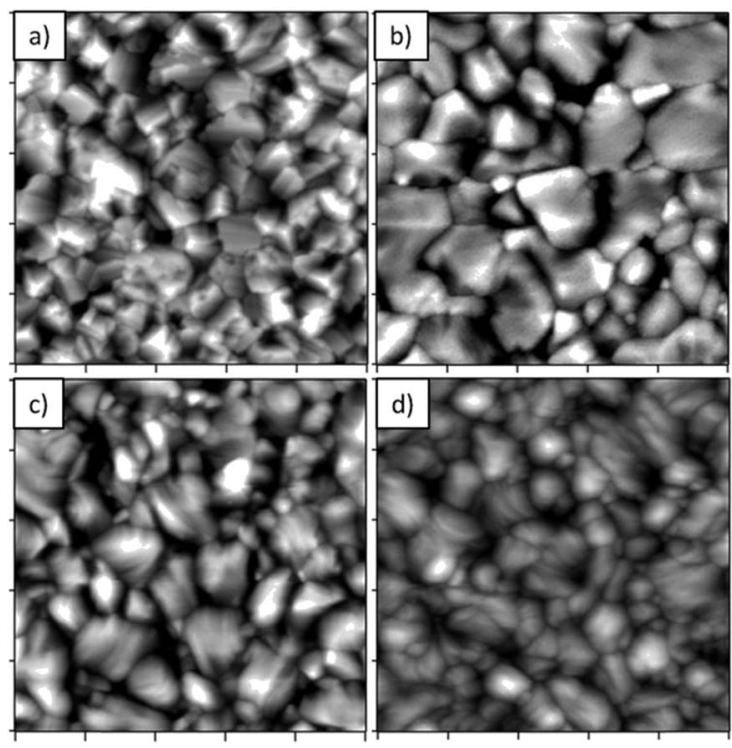

Fig. 4 Oversaturation negatively impacts the grain size. Tappingmode atomic force microscopy topography images of FAI perovskite films. All images are $5 \mu \mathrm{m} \times 5 \mu \mathrm{m}$ with a $Z$ range of $140 \mathrm{~nm}$. (a) Undersaturated perovskite, deficient in FAI. Root-mean-square (RMS) roughness was $32 \mathrm{~nm}$. (b) Saturated perovskite with $970 \mathrm{~nm} \pm 420 \mathrm{~nm}$ grain size and RMS roughness of $36 \mathrm{~nm}$. (c) Oversaturated and then de-saturated perovskite with a grain size of $730 \mathrm{~nm} \pm 360 \mathrm{~nm}$ and a $32 \mathrm{~nm}$ RMS roughness. (d) Highly oversaturated and de-saturated perovskite with $500 \mathrm{~nm} \pm 230 \mathrm{~nm}$ grains and $22 \mathrm{~nm}$ surface roughness.

with expectations because FAI is deposited on the top surface. Iodine first displaces chloride ions on the top and gradually proceeds down to the bottom. Also, with increasing amounts of iodine deposited, fewer chlorine atoms remain in the perovskite. Therefore, oversaturation depletes the concentration of chloride ions and provides an additional mechanism beyond the grain size that likely affects efficiency. It is possible that the chlorine ions in the less saturated films have improved carrier lifetime..$^{30}$ By adjusting the degree of oversaturation, the chlorine concentration within the film can be tuned to optimize solar cell performance.

\section{Stability}

Temperature stability is important for all solar cells because they are required to operate under the heat of the sun. It is especially important for the CVD process because perovskite is grown at high temperatures. FAI is reported to have greater thermal stability than MAI. ${ }^{17}$ A simple test of MAI and FAI based perovskite films grown by CVD shows that the decay rate at $120{ }^{\circ} \mathrm{C}$ in air appears to be slower for FAI (Fig. 6).

A substrate with 4 samples from the "oversaturated" growth was chosen to monitor stability. Samples were stored in a nitrogen glovebox between measurements. The devices were found to be stable up to 155 days. The highest efficiency measurement of $14.2 \%$ was taken 42 days after fabrication. After 155 days, the average efficiency increased from $11.3 \%$ to $11.8 \%$. Similarly, small improvements were observed previously with MAI-based perovskite cells made using CVD. ${ }^{13}$ This 


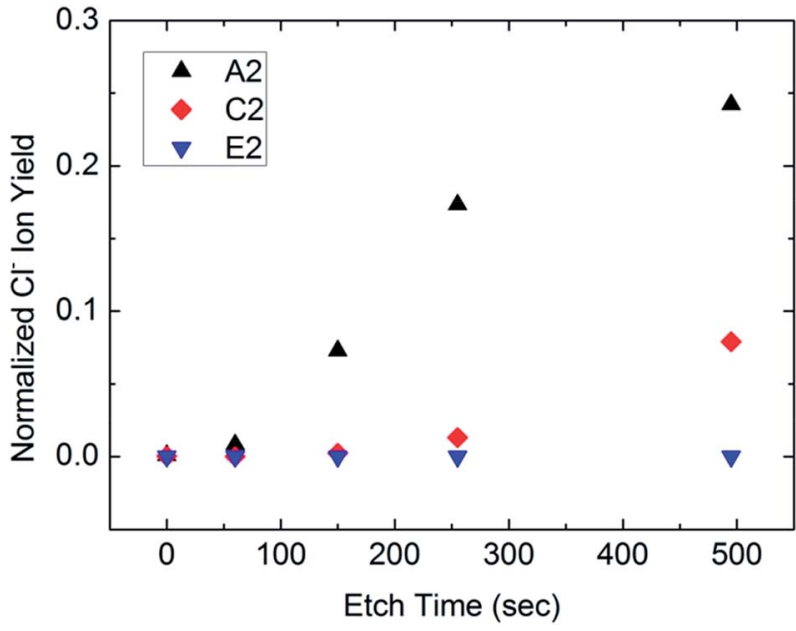

Fig. 5 Chlorine concentration decreases with increasing saturation. The figure shows normalized chlorine counts from time of flight secondary ion mass spectroscopy as a function of etch times for three samples (A2, C2, and E2) with different levels of saturation. Etch time correlates with depth within the film, where $0 \mathrm{~s}$ represents the top surface and $500 \mathrm{~s}$ has reached the glass substrate. Chloride ions were not present in significant quantities on the top surface for all 3 samples. Samples A2 and C2 had chlorine concentrations that increase with increasing depth. Increasing levels of FAl saturation correlates with lower counts of chloride ions. For example, sample E2 which had the highest level of saturation had a negligible concentration of chlorine throughout the film.

improvement in efficiency may be due to the improved charge transport properties of spiro-MeOTAD induced by air exposure, ${ }^{31}$ but the mechanism aside, the important issue is that the cells do not decay with time in an inert environment, which provides hope for stable cells with proper encapsulation (Table 2).

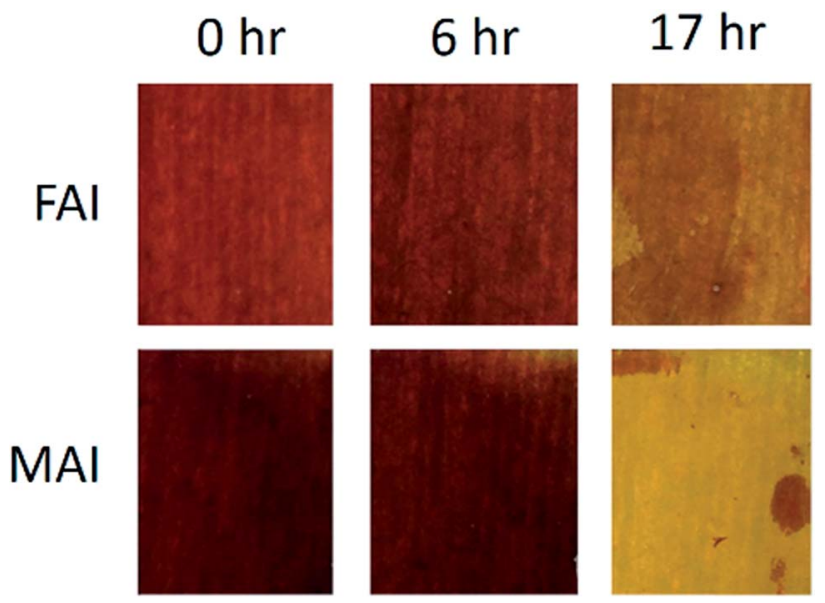

Fig. 6 Perovskite films made with FAI are more thermally stable than MAI. Samples are left on a hot plate at $120{ }^{\circ} \mathrm{C}$ in air with $\sim 50 \%$ relative humidity. The MAl sample begins to decay at the edges after $6 \mathrm{~h}$, while the FAl showed no sign of decay. After $17 \mathrm{~h}$, the MAl film nearly completely decayed, while the FAl showed signs of decay but maintained a darker color. Perovskite films prepared on glass are approximately $300 \mathrm{~nm}$ thick. Photographs are taken with illumination from the bottom.
Table 2 Cells are stable up to 155 days. A substrate with 4 devices was used to monitor stability. The average of performance of the 4 devices as well as the champion device is shown

\begin{tabular}{llllll}
\hline Time & Sample & $V_{\mathrm{oc}}$ & $J_{\text {sc }}\left(\mathrm{mA} \mathrm{cm}^{-2}\right)$ & FF & PCE $(\%)$ \\
\hline Fresh & Champion & 0.98 & 21.5 & 59 & 12.5 \\
Fresh & Average & 0.98 & 20.2 & 57 & 11.3 \\
42 days & Champion & 1.03 & 20.9 & 66 & 14.2 \\
104 days & Champion & 1.03 & 20.2 & 60 & 12.5 \\
155 days & Champion & 1.02 & 21.8 & 60 & 13.4 \\
155 days & Average & 1.02 & 19.9 & 58 & 11.8 \\
\hline
\end{tabular}

\section{Methods}

\section{Substrate preparation}

FTO glass (Pilkington, $7 \Omega / \gamma$ ) was patterned by etching with $\mathrm{Zn}$ powder and $2 \mathrm{M} \mathrm{HCl}$ followed by brushing the surface with detergent, rinsing with deionized water, and sonication in 2-propanol. A compact layer of $\mathrm{TiO}_{2}$ was then deposited via spray pyrolysis using a precursor solution of acetylacetone, Ti(Iv) isopropoxide, and anhydrous ethanol $(3: 3: 2)$ on a pre-heated hot plate at $480^{\circ} \mathrm{C}$. This layer was approximately $65 \mathrm{~nm}$ thick (profilometer, Bruker).

\section{Perovskite film growth by CVD}

Perovskite films were grown in a two-step process where lead halide was first deposited onto substrates, followed by CVD deposition of FAI (Dyesol) which converted the film to perovskite. Unless stated otherwise, all perovskite films were prepared by depositing a $100 \mathrm{~nm}$ layer of lead chloride onto substrates by thermal evaporation (at $2.0 \times 10^{-2} \mathrm{~Pa}$, approximately 0.1 to $0.4 \AA \mathrm{A} \mathrm{s}^{-1}$, using $\mathrm{PbCl}_{2}$ powder, Sigma-Aldrich). The thickness was monitored with a quartz-crystal microbalance and additionally measured using a profilometer. Substrates pre-deposited with $\mathrm{PbCl}_{2}$ were loaded into a 2-zone CVD furnace, where the first zone was loaded with $\sim 1 \mathrm{~g}$ of solid FAI powder and the second zone with substrates. For all devices reported in Fig. 3, substrates were ramped up to $160^{\circ} \mathrm{C}$, and then FAI was ramped to $180{ }^{\circ} \mathrm{C}$. Essentially, all FAI absorption occurs when the substrate is at $160{ }^{\circ} \mathrm{C}$. This temperature was measured with a thermocouple placed inside of the CVD tube to guarantee a temperature measurement similar to the substrate. All devices were grown in a $6 \mathrm{~cm}$ region between labels B and D marked on the CVD tube to maximize batch uniformity (Fig. 1). Total FAI sublimation time was approximately $30 \mathrm{~min}$, where FAI was held at $180^{\circ} \mathrm{C}$ for $\sim 6-16$ $\mathrm{min}$, and $\sim 20 \mathrm{~min}$ was required for ramp up and cool down. The amount of FAI consumed was typically $\sim 50 \mathrm{mg}$ or less. FAI temperature was allowed to cool below $160{ }^{\circ} \mathrm{C}$ and substrate heating was turned off.

\section{Device fabrication}

Solar cell device fabrication was completed by spin-coating a hole transport layer that consists of a mixture of three materials: spiroMeOTAD (2,2',7,7'-tetrakis( $N, N$-di- $p$-methoxy-phenylamine)-9, $9^{\prime}$ - 
spirobifluorene (Suna Tech Inc.) dissolved in chlorobenzene (70 $\mathrm{mg} \mathrm{mL}^{-1}$ ), $20 \mu \mathrm{L}$ of Li-bis(trifluoromethanesulfonyl)-imide (LiTFSI, Sigma) dissolved in acetronitrile $(50 \mathrm{mg} / 100 \mu \mathrm{L})$, and $30 \mu \mathrm{L}$ of tert-butylpyridine ( $t$-BP, Sigma). Top electrodes were gold, deposited by thermal evaporation $\left(<1.0 \times 10^{-6}\right.$ Torr, at $0.1-0.2 \AA_{\mathrm{s}}^{-1}$ ) through a shadow mask. The nominal solar cell active area ranged from $0.04-0.169 \mathrm{~cm}^{2}$, in addition to one batch of solar cells of $1 \mathrm{~cm}^{2}$.

\section{ToF-SIMS measurements}

Time of flight secondary ion mass spectrometry (ToF-SIMS) measurements were performed to study the role of chlorine. The $\mathrm{Cl}^{-}$ion signal was normalized based on its ratio to the total ion yield in negative ion extraction mode. Chlorine counts were binned from 34.92 to 35.02 amu. We thank ULVAC-PHI, Inc. for helping with ToF-SIMS measurements.

\section{Solar cell measurements}

Current-voltage $(I-V)$ characteristics of solar cells were measured under 1-sun illumination (AM $1.5 \mathrm{G}, 100 \mathrm{~mW} \mathrm{~cm}^{-2}$ ) using a solar simulator (Newport Oriel Sol 1A) and a Keithley 2400 source meter. All measurements were performed without a mask, in ambient air at $\sim 23-25{ }^{\circ} \mathrm{C}$ and a relative humidity of $\sim 40-50 \%$. All measurements were made with a sweep rate of $\sim 0.4 \mathrm{~V} \mathrm{~s}^{-1}$ with a range of -0.1 to $1.1 \mathrm{~V}$, and $60 \mathrm{~s}$ of light preillumination.

\section{Film characterization}

X-ray diffraction spectra were measured using a D8 Discover (Bruker). Atomic Force Microscopy images were taken using an Asylum MFP-3D in AC mode. UV-vis absorbance spectra were measured on a Jasco V-670 spectrometer. X-ray photoelectron spectroscopy was performed with an AXIS Ultra DLD (Kratos Analytical Ltd.) using monochromated Al K $\alpha$ X-rays.

\section{Conclusions}

Tight process control may be at odds with a cost-effective process. A more robust process demonstrating stability and reasonably high efficiency is more desirable. In the reversible process (i.e. oversaturation), desorption of FAI appears selflimiting, making the FAI oversaturation process both robust and convenient to control. This process produced uniform films along the length of the CVD tube and was easier to reproduce from batch to batch. By adjusting the degree of FAI oversaturation in the perovskite film, the chlorine content can be adjusted, subsequently changing performance and stability. This process demonstrated efficiencies as high as $14.2 \%$, with a batch average of $11.5 \% \pm 1.0 \%$. Cells with sizes as high as $1 \mathrm{~cm}^{2}$ were fabricated by reversible formation, with future modules likely being limited only by the size of the CVD tube. Chlorine concentrations in perovskite films were studied by time-of-flight secondary ion mass spectroscopy and may play an important role in cell efficiency and stability.

\section{Acknowledgements}

This work was supported by funding from the Energy Materials and Surface Sciences Unit of the Okinawa Institute of Science and Technology Graduate University. We thank ULVAC-PHI, Inc. for helping with ToF-SIMS measurements. We thank Steven D. Aird, the Technical Editor at Okinawa Institute of Science and Technology Graduate University for valuable suggestions in revising the manuscript.

\section{Notes and references}

1 M. M. Aman, K. H. Solangi, M. S. Hossain, A. Badarudin, G. B. Jasmon, H. Mokhlis, A. H. A. Bakar and S. N. Kazi, Renewable Sustainable Energy Rev., 2015, 41, 1190-1204.

2 M. Bazilian, I. Onyeji, M. Liebreich, I. MacGill, J. Chase, J. Shah, D. Gielen, D. Arent, D. Landfear and S. Zhengrong, Renewable Energy, 2013, 53, 329-338.

3 N.-G. Park, Mater. Today, 2015, 18(2), 65-72.

4 W. S. Yang, J. H. Noh, N. J. Jeon, Y. C. Kim, S. Ryu, J. Seo and S. I. Seok, Science, 2015, aaa9272.

5 S. Razza, F. Di Giacomo, F. Matteocci, L. Cinà, A. L. Palma, S. Casaluci, P. Cameron, A. D'Epifanio, S. Licoccia, A. Reale, T. M. Brown and A. Di Carlo, J. Power Sources, 2015, 277, 286-291.

6 J. Burschka, N. Pellet, S.-J. Moon, R. Humphry-Baker, P. Gao, M. K. Nazeeruddin and M. Grätzel, Nature, 2013, 499, 316319.

7 M. M. Lee, J. Teuscher, T. Miyasaka, T. N. Murakami and H. J. Snaith, Science, 2012, 338, 643-647.

8 Q. Chen, H. Zhou, Z. Hong, S. Luo, H.-S. Duan, H.-H. Wang, Y. Liu, G. Li and Y. Yang, J. Am. Chem. Soc., 2013, 136, 622625.

9 J. H. Kim, S. T. Williams, N. Cho, C.-C. Chueh and A. K.-Y. Jen, Adv. Energy Mater., 2015, 5, 1401229.

10 K. Hwang, Y.-S. Jung, Y.-J. Heo, F. H. Scholes, S. E. Watkins, J. Subbiah, D. J. Jones, D.-Y. Kim and D. Vak, Adv. Mater., 2015, DOI: 10.1002/adma.201404598.

11 M. Liu, M. B. Johnston and H. J. Snaith, Nature, 2013, 501, 395-398.

12 L. K. Ono, S. Wang, Y. Kato, S. R. Raga and Y. Qi, Energy Environ. Sci., 2014, 7, 3989-3993.

13 M. R. Leyden, L. K. Ono, S. R. Raga, Y. Kato, S. Wang and Y. B. Qi, J. Mater. Chem. A, 2014, 2, 18742-18745.

14 A. T. Barrows, A. J. Pearson, C. K. Kwak, A. D. F. Dunbar, A. R. Buckley and D. G. Lidzey, Energy Environ. Sci., 2014, 7, 2944-2950.

15 J.-H. Park and T. S. Sudarshan, Chemical Vapor Deposition, ASM International, 2001.

16 X.-T. Yan and Y. Xu, Chemical Vapour Deposition: An Integrated Engineering Design for Advanced Materials, Springer Science \& Business Media, 2010.

17 G. E. Eperon, S. D. Stranks, C. Menelaou, M. B. Johnston, L. M. Herz and H. J. Snaith, Energy Environ. Sci., 2014, 7, 982.

18 N. Pellet, P. Gao, G. Gregori, T.-Y. Yang, M. K. Nazeeruddin, J. Maier and M. Grätzel, Angew. Chem., Int. Ed., 2014, 53, 3151-3157. 
19 S. Pang, H. Hu, J. Zhang, S. Lv, Y. Yu, F. Wei, T. Qin, H. Xu, Z. Liu and G. Cui, Chem. Mater., 2014, 26, 1485-1491.

20 S. Lv, S. Pang, Y. Zhou, N. P. Padture, H. Hu, L. Wang, X. Zhou, H. Zhu, L. Zhang, C. Huang and G. Cui, Phys. Chem. Chem. Phys., 2014, 16, 19206.

21 T. M. Koh, K. Fu, Y. Fang, S. Chen, T. C. Sum, N. Mathews, S. G. Mhaisalkar, P. P. Boix and T. Baikie, J. Phys. Chem. C, 2013, 118, 16458-16462.

22 M. Hu, L. Liu, A. Mei, Y. Yang, T. Liu and H. Han, J. Mater. Chem. A, 2014, 2, 17115-17121.

23 F. C. Hanusch, E. Wiesenmayer, E. Mankel, A. Binek, P. Angloher, C. Fraunhofer, N. Giesbrecht, J. M. Feckl, W. Jaegermann, D. Johrendt, T. Bein and P. Docampo, J. Phys. Chem. Lett., 2014, 5, 2791-2795.

24 R. S. Sanchez, V. Gonzalez-Pedro, J.-W. Lee, N.-G. Park, Y. S. Kang, I. Mora-Sero and J. Bisquert, J. Phys. Chem. Lett., 2014, 5, 2357-2363.
25 S. Aharon, A. Dymshits, A. Rotem and L. Etgar, J. Mater. Chem. A, 2015, 3, 9171-9178.

26 G. E. Eperon, V. M. Burlakov, A. Goriely and H. J. Snaith, ACS Nano, 2014, 8, 591-598.

27 N. J. Jeon, J. H. Noh, W. S. Yang, Y. C. Kim, S. Ryu, J. Seo and S. I. Seok, Nature, 2015, 517, 476-480.

28 J.-W. Lee, D.-J. Seol, A.-N. Cho and N.-G. Park, Adv. Mater., 2014, 26, 4991-4998.

29 C. C. Stoumpos, C. D. Malliakas and M. G. Kanatzidis, Inorg. Chem., 2013, 52, 9019-9038.

30 D. W. deQuilettes, S. M. Vorpahl, S. D. Stranks, H. Nagaoka, G. E. Eperon, M. E. Ziffer, H. J. Snaith and D. S. Ginger, Science, 2015, 348, 683-686.

31 Z. Hawash, L. K. Ono, S. R. Raga, M. V. Lee and Y. B. Qi, Chem. Mater., 2015, 27, 562-569. 